\title{
Health claims database study of cyclosporine ophthalmic emulsion treatment patterns in dry eye patients
}

This article was published in the following Dove Press journal:

Therapeutics and Clinical Risk Management

24 October 2013

Number of times this article has been viewed

\author{
Karl G Stonecipher' \\ Jenny Chia ${ }^{2}$ \\ Ahunna Onyenwenyi ${ }^{2}$ \\ Linda Villanueva ${ }^{2}$ \\ David A Hollander ${ }^{2}$ \\ 'TLC Laser Eye Centers, Greensboro, \\ NC, ${ }^{2}$ Allergan, Inc., Irvine, CA, USA
}

Correspondence: Karl G Stonecipher

TLC Laser Eye Centers, 3312

Battleground Ave, Greensboro,

NC 27410, USA

$\mathrm{Tel}+\mathrm{I} 3362888823$

Email stonenc@aol.com
Background: Dry eye is a multifactorial, symptomatic disease associated with ocular surface inflammation and tear film hyperosmolarity. This study was designed to assess patterns of topical cyclosporine ophthalmic emulsion $0.05 \%$ (Restasis $^{\circledR}$ ) use in dry eye patients and determine if there were any differences in use based on whether dry eye is physician-coded as a primary or nonprimary diagnosis.

Methods: Records for adult patients with a diagnosis of dry eye at an outpatient visit from January 1, 2008 to December 31, 2009 were selected from Truven Health MarketScan ${ }^{\circledR}$ Research Databases. The primary endpoint was percentage of patients with at least one primary versus no primary dry eye diagnosis who filled a topical cyclosporine prescription. Data analyzed included utilization of topical corticosteroids, oral tetracyclines, and punctal plugs.

Results: The analysis included 576,416 patients, accounting for 875,692 dry eye outpatient visits: $74.7 \%$ were female, $64.2 \%$ were ages $40-69$ years, and $84.4 \%$ had at least one primary dry eye diagnosis. During 2008-2009, 15.9\% of dry eye patients with a primary diagnosis versus $6.5 \%$ with no primary diagnosis filled at least one cyclosporine prescription. For patients who filled at least one prescription, the mean months' supply of cyclosporine filled over 12 months was 4.44. Overall, $33.9 \%$ of dry eye patients filled a prescription for topical cyclosporine, topical corticosteroid, or oral tetracycline over 2 years.

Conclusion: Patients with a primary dry eye diagnosis were more likely to fill a topical cyclosporine prescription. Although inflammation is key to the pathophysiology of dry eye, most patients seeing a physician for dry eye may not receive anti-inflammatory therapies.

Keywords: corticosteroids, cyclosporine, dry eye syndromes, inflammation, medication adherence

\section{Introduction}

Dry eye is a multifactorial, symptomatic disease associated with increased osmolarity of the tear film and ocular surface inflammation, which leads to ocular discomfort and visual disturbance. ${ }^{1}$ This definition has evolved in recent years from the traditional classification of dry eye simply as a disorder of either insufficient tear production or excessive tear evaporation. ${ }^{2}$ Dry eye disease is common and is currently estimated to affect 3.25 million women and 1.68 million men aged 50 years and over in the US., Dry eye has been shown to contribute to difficulties with everyday activities, including driving, using a computer, reading, and completing professional work. ${ }^{5,6}$

It is now understood that the tear-secreting glands and the ocular surface form an integrated functional lacrimal unit via sensory and autonomic nerves designed to maintain the health of the ocular surface. ${ }^{1}$ Dysfunction in any component of this 
lacrimal unit leads to tear film instability and inflammation. An International Task Force of 17 dry eye specialists using a Delphi consensus technique has published treatment guidelines for dry eye based on four levels of dry eye severity. ${ }^{7}$ There was consensus by the International Task Force panel that inflammation either triggers or maintains most cases of dry eye, even when inflammation is not clinically visible. Currently, artificial tears are the most common initial approach used to relieve symptoms in patients with mild dry eye. Antiinflammatory therapies, namely topical cyclosporine and corticosteroids, were recommended by the International Task Force for patients beginning at disease level 2 (moderate to severe symptoms, mild corneal staining, conjunctival staining) followed by options such as tetracyclines and punctal plugs beginning at disease level 3 (severe symptoms, marked or central corneal staining, filamentary keratitis). ${ }^{7}$

Dry eye is one of the leading reasons for patient visits to eye care specialists. ${ }^{8}$ Although topical cyclosporine ophthalmic emulsion $0.05 \%$ (Restasis $^{\circledR}$; Allergan, Inc., Irvine, CA, USA) was approved in 2003 to increase tear production in patients with reduced tear production presumed due to ocular inflammation, the patterns of clinical use of cyclosporine in dry eye disease have not been well defined. The primary objective of this study was to use a large US insurance claims database to evaluate the percentage of adults with dry eye as a primary or secondary diagnosis who filled a prescription for cyclosporine. Our hypothesis was that patients with a primary diagnosis of dry eye, as recorded by a physician, would be more likely to be treated with prescription treatment such as cyclosporine. Additionally, the study sought to define better the demographics and characteristics of dry eye patients who fill a prescription for cyclosporine, as well as to understand the patterns of prescription fills for both topical cyclosporine and other options prescribed to treat dry eye.

\section{Materials and methods}

The Truven Health MarketScan ${ }^{\circledR}$ Commercial and Medicare Supplemental Databases for 2007 through 2010 were the sources of data for this study. The Truven Health MarketScan Commercial Database contains health claims records from individuals covered by employer-sponsored health insurance and their dependents. Pharmacy claims data include the date that a prescription medication was filled, dosage and quantity supplied, and cost of the medication. The Truven Health MarketScan Medicare Supplemental Database focuses on patients 65 years of age and over with standard Medicare coverage plus employer-paid commercial plans. The database includes both employer-paid and Medicare-paid components of health care. The databases are fully compliant with the Health Portability and Accountability Act of 1996, and all data included are deidentified to protect the privacy of patients and providers. Institutional review board approval of the study was not sought or required because, by US federal code, studies using databases that have anonymized all private information do not fall under institutional review board jurisdiction.

Medical claims data were reviewed to identify adult patients (18 years of age or older) who had a diagnosis of dry eye or who had punctal plug placement at an outpatient visit during the study period from January 1, 2008 to December 31, 2009. For the analysis, these visits were termed dry eye visits. Dry eye diagnosis was identified by International Classification of Diseases, Ninth Revision code 370.33 (keratoconjunctivitis sicca not specified as Sjogren's), 375.15 (tear film insufficiency unspecified), or 710.2 (sicca syndrome). Punctal plug placement was identified by Current Procedural Terminology code 68760 (closure of lacrimal punctum by thermocauterization, ligation, or laser surgery by plug) or 68761 (closure of lacrimal punctum by plug). The first observation of dry eye as a primary diagnosis or coexisting condition or first punctal plug placement within the January 1, 2008 to December 31, 2009 claim period was set as the index date.

For categorization, primary dry eye patients were defined as patients with at least one primary diagnosis of dry eye coded at an outpatient visit over the study period. Patients who underwent placement of punctal plugs were also categorized as having primary dry eye, regardless of whether they had a primary or nonprimary dry eye diagnosis. Nonprimary dry eye patients were defined as patients with at least one nonprimary diagnosis and no primary diagnosis of dry eye over the study period. Claims for these patients identified dry eye only as a coexisting condition. A post hoc analysis was also performed in which a chronic primary dry eye subgroup was defined as patients with at least three outpatient visits separated by at least 3 months over 2 years, with dry eye identified as the primary diagnosis at each visit.

The primary endpoint was the percentage of patients with a primary dry eye diagnosis versus no primary dry eye diagnosis who filled a prescription for topical cyclosporine during the study period of January 1, 2008 to December 31, 2009. The demographics of all dry eye patients as well as of those patients who filled a prescription for topical cyclosporine were evaluated. Additional assessments of the use of topical cyclosporine included the percentage of patients who filled 
a cyclosporine prescription within 30 days of an outpatient visit with a dry eye diagnosis, the number of months' supply of cyclosporine filled over the course of 12 months after the initial fill, and the percentage of patients who filled only a single 30-day supply of topical cyclosporine. In addition, the use of other prescription therapies (oral tetracyclines, topical corticosteroids) and procedures (punctal plugs) for dry eye was evaluated and compared among the different categories of dry eye.

SAS version 9.2 (SAS Institute Inc., Cary, NC, USA) was used for the data analysis. The data were summarized with description statistics. Categorical variables were compared with Pearson chi-square tests.

\section{Results}

A total of 576,416 dry eye patients (total dry eye group) met the study inclusion criteria and were included in the analysis. This total patient population included patients who had either at least one primary dry eye diagnosis, at least one nonprimary dry eye diagnosis, or a punctal plug placement over the course of 875,692 dry eye outpatient visits during the 2008-2009 study period. Insurance coverage consisted of an employersponsored commercial plan for $76.0 \%(438,337)$ of the patients and Medicare with an employer-provided Medicare Supplemental plan for $24.0 \%(138,079)$ of the patients.

Demographic characteristics of the dry eye patients are listed in Table 1 . Three quarters $(74.7 \%)$ of the patients were female. Patients in the age range of 50-59 years represented $27.0 \%$ of the dry eye population, and most patients $(64.2 \%)$ were in the age range of 40-69 years on the index date. A similar percentage of patients were in the 18-39 age range $(17.7 \%)$ relative to the $70+$ age range $(18.1 \%)$.

Among the total study population, 84.4\% (486,390) of patients were categorized as primary dry eye patients
(Table 2). A total of 480,111 (83.3\%) patients received at least one primary diagnosis of dry eye during the study period. In addition, 6,279 (1.3\%) patients received punctal plugs during the study period without any accompanying dry eye diagnosis but were also categorized as having primary dry eye. Dry eye was identified on medical claims as a nonprimary, coexisting condition in $15.6 \%$ $(90,026)$ of the patients. A relatively small percentage of the patients $(6.6 \%)$ met the study criteria for chronic primary dry eye.

Overall, $14.4 \%$ of all dry eye patients filled at least one prescription for topical cyclosporine during the 2-year study period. Patients with a primary diagnosis of dry eye were more likely than patients with a nonprimary diagnosis of dry eye to be treated with cyclosporine, as $15.9 \%$ of patients with primary dry eye compared with $6.5 \%$ of patients with nonprimary dry eye filled one or more prescriptions for cyclosporine over the 2-year period ( $P<0.0001$, Table 2$)$. Patients with chronic primary dry eye were most apt to be treated with cyclosporine. Approximately half of the patients categorized with chronic primary dry eye (48.2\%) filled one or more prescriptions for cyclosporine over the 2-year study period. Overall, primary dry eye patients were 2.8 times more likely to fill a prescription for cyclosporine within 30 days of a visit than nonprimary dry eye patients $(10.4 \%$ versus $3.6 \%, P<0.0001$, Table 2).

Of the 83,089 patients who filled a prescription for cyclosporine, 77,244 (93.0\%) had a primary diagnosis of dry eye. The demographics of the patients who filled a prescription for cyclosporine (Table 1) were generally similar to those of all patients with dry eye, but an even higher percentage were female $(83.8 \%)$. Patients in the age range of 50-59 years represented $31.3 \%$ of all patients who filled a prescription for cyclosporine.

Table I Demographics of all dry eye patients and dry eye patients treated with cyclosporine, $n$ (\%)

\begin{tabular}{|c|c|c|c|c|c|}
\hline \multirow[t]{2}{*}{ Characteristic } & \multirow{2}{*}{$\begin{array}{l}\text { All patients } \\
\text { Total } \\
(n=576,416)\end{array}$} & \multicolumn{4}{|c|}{ Patients who filled prescription for cyclosporine } \\
\hline & & $\begin{array}{l}\text { Total } \\
(n=83,089)\end{array}$ & $\begin{array}{l}\text { Primary dry eye } \\
(n=77,244)\end{array}$ & $\begin{array}{l}\text { Chronic primary dry eye } \\
(n=|8,47|)\end{array}$ & $\begin{array}{l}\text { Nonprimary dry eye } \\
(n=5,845)\end{array}$ \\
\hline \multicolumn{6}{|l|}{ Age } \\
\hline $18-29$ & $42,435(7.4)$ & $3,730(4.5)$ & $3,550(4.6)$ & $774(4.2)$ & $180(3.1)$ \\
\hline $30-39$ & $59,203(10.3)$ & $7,179(8.6)$ & $6,772(8.8)$ & $1,484(8.0)$ & $407(7.0)$ \\
\hline $40-49$ & $106,203(18.4)$ & $14,316(17.2)$ & $13,424(17.4)$ & $3,191(17.3)$ & $892(15.3)$ \\
\hline $50-59$ & $155,348(27.0)$ & $26,034(31.3)$ & $24,129(31.2)$ & $5,943(32.2)$ & $1,905(32.6)$ \\
\hline $60-69$ & 108,663 (18.9) & $17,860(2 \mid .5)$ & $16,342(2 \mid .2)$ & $3,854(20.9)$ & I,5 I $8(26.0)$ \\
\hline 70-79 & $59,912(10.4)$ & $8,716(10.5)$ & $8,122(10.5)$ & 2,067 (II.2) & $594(10.2)$ \\
\hline $80+$ & $44,652(7.7)$ & $5,254(6.3)$ & $4,905(6.4)$ & $\mathrm{I}, \mathrm{I} 58(6.3)$ & $349(6.0)$ \\
\hline \multicolumn{6}{|l|}{ Sex } \\
\hline Male & 145,986 (25.3) & $|3,47|(16.2)$ & $12,367(16.0)$ & $2,544(13.8)$ & I,I04 (I8.9) \\
\hline Female & $430,430(74.7)$ & $69,618(83.8)$ & $64,877(84.0)$ & $15,927(86.2)$ & $4,74 I(8 I . I)$ \\
\hline
\end{tabular}


Table 2 Percentage of dry eye patients with cyclosporine prescription fill

\begin{tabular}{llll}
\hline Patient group & $\begin{array}{l}\text { n (\% of total } \\
\text { dry eye) }\end{array}$ & $\begin{array}{l}\text { Percentage of patients with } \geq \mathbf{I} \\
\text { cyclosporine prescription filled } \\
\text { during study period }\end{array}$ & $\begin{array}{l}\text { Percentage of patients with cyclosporine } \\
\text { prescription filled within 30 days of dry } \\
\text { eye outpatient visit }\end{array}$ \\
\hline All dry eye patients & $576,416(100)$ & 14.4 & 9.3 \\
Primary dry eye patients & $486,390(84.4)$ & 15.9 & 10.4 \\
Chronic primary dry eye patients & $38,290(6.6)$ & 48.2 & 39.1 \\
Nonprimary dry eye patients & $90,026(15.6)$ & 6.5 & 3.6 \\
\hline
\end{tabular}

A greater likelihood of cyclosporine prescription fill in primary dry eye than in nonprimary dry eye was also seen when the data were analyzed at the level of visits rather than patients. There were 875,692 dry eye visits in all, including $721,973(82.4 \%)$ in which there was a primary diagnosis of dry eye or punctal plug placement and $153,719(17.6 \%)$ in which the diagnosis of dry eye was identified as a coexisting condition. A prescription for cyclosporine was filled within 30 days after $8.4 \%$ of primary dry eye visits versus $4.7 \%$ of nonprimary dry eye visits $(P<0.0001)$. Patients who filled a prescription for cyclosporine were seen at a mean of $1.54 \pm 0.01$ dry eye outpatient visits during the study period prior to receiving this medication. In the chronic primary dry eye subpopulation, patients had a mean of $2.22 \pm 0.02$ office visits prior to receiving and filling a prescription for topical cyclosporine.

Patterns of use of topical cyclosporine were evaluated among patients who filled at least one prescription for topical cyclosporine and had at least 12 months of follow-up data available after the first fill. A total of 62,801 patients satisfied these criteria for analysis (Table 3). The mean months' supply of cyclosporine medication filled over 12 months for these patients was $4.44 \pm 0.015$ months, although $18.0 \%$ of all dry eye patients who filled a cyclosporine prescription only filled a 1-month supply over 12 months of follow-up. Among patients with a filled cyclosporine prescription, a greater percentage of nonprimary dry eye patients $(22.8 \%)$ relative to the chronic primary subgroup of dry eye patients (10.9\%) filled only a 1-month supply of medication during 12 months of follow-up $(P<0.0001)$.
Use of other medical treatments for dry eye, alone or in combination with cyclosporine, was evaluated. Over the 2-year study period, approximately one in ten patients filled a prescription for an oral tetracycline regardless of whether they were categorized as primary dry eye (10.7\%) or nonprimary dry eye $(9.2 \%$, Table 4$)$. Over the same period, $20.1 \%$ of primary dry eye patients and $15.0 \%$ of nonprimary dry eye patients filled at least one prescription for a topical corticosteroid (Table 4). Patients who filled a prescription for topical cyclosporine were more likely to fill prescriptions for topical corticosteroids and oral tetracyclines over the 2-year study period. The topical corticosteroids most commonly filled by dry eye patients are listed in Table 5 .

A total of 61,039 patients had punctal plugs placed within the study period. Only 19,049 (31.2\%) of these patients also filled a prescription for cyclosporine during the same 2-year period. A total of 9,903 of the patients who both filled a prescription for cyclosporine and had punctal plugs placed during 2008-2009 had data available for the 12 months before and after the first date of the plugs. Analysis of the timing of punctal plug placement and cyclosporine prescription fills in these patients showed that $59.0 \%$ of the patients filled a prescription for cyclosporine prior to punctal plug placement.

Overall, $38.5 \%$ of dry eye patients filled a prescription for topical cyclosporine, a topical corticosteroid, or an oral tetracycline, or underwent punctal plug placement during the study period (Table 6). A prescription for topical cyclosporine, a topical corticosteroid, or an oral tetracycline was filled by $35.5 \%$ of primary dry eye patients compared

Table 3 Adherence to cyclosporine based on drug supply for patients who filled at least one prescription and had 12 months of data available after the first date of cyclosporine fill

\begin{tabular}{llll}
\hline Patient group & $\begin{array}{l}\text { Patients with } \geq \mathbf{I} \text { cyclosporine } \\
\text { prescription fill and I 2 months of data } \\
\text { after first fill, } \mathbf{n} \text { (\% of total dry eye) }\end{array}$ & $\begin{array}{l}\text { Months of treatment } \\
\text { filled over I year, } \\
\text { mean (SD) }\end{array}$ & $\begin{array}{l}\text { Percentage of patients } \\
\text { with only I month } \\
\text { supply over I year }\end{array}$ \\
\hline All dry eye patients & $62,80 I(100)$ & $4.44(0.015)$ & 18.0 \\
Primary dry eye patients & $58,673(93.8)$ & $4.47(0.016)$ & 17.7 \\
Chronic primary dry eye patients & $15,262(25.5)$ & $5.35(0.034)$ & 10.9 \\
Nonprimary dry eye patients & $4,218(6.2)$ & $4.00(0.057)$ & 22.8 \\
\hline
\end{tabular}

Abbreviation: SD, standard deviation. 
Table 4 Patients filling prescriptions for other dry eye treatments ${ }^{\mathrm{a}}$ alone or in addition to cyclosporine in 2008-2009, n (\%)

\begin{tabular}{|c|c|c|c|c|c|c|}
\hline \multirow{2}{*}{$\begin{array}{l}\text { Prescription other } \\
\text { than cyclosporine }\end{array}$} & \multicolumn{3}{|c|}{ Patients with primary dry eye diagnosis } & \multicolumn{3}{|c|}{ Patients with nonprimary dry eye diagnosis } \\
\hline & $\begin{array}{l}\text { All patients } \\
(n=486,390)\end{array}$ & $\begin{array}{l}\text { Patients with } \geq I \\
\text { cyclosporine } \\
\text { prescription fill } \\
(n=77,244)\end{array}$ & $\begin{array}{l}\text { Patients with } \\
\text { no cyclosporine } \\
\text { prescription fill } \\
(n=409,146)\end{array}$ & $\begin{array}{l}\text { All patients } \\
(n=90,026)\end{array}$ & $\begin{array}{l}\text { Patients with } \geq I \\
\text { cyclosporine } \\
\text { prescription fill } \\
(n=5,845)\end{array}$ & $\begin{array}{l}\text { Patients with } \\
\text { no cyclosporine } \\
\text { prescription fill } \\
(n=84,18 I)\end{array}$ \\
\hline Oral tetracycline & $51,986(10.7)$ & $12,437(16.1)$ & $39,549(9.7)$ & $8,268(9.2)$ & $831(14.2)$ & $7,437(8.8)$ \\
\hline Topical corticosteroid & $97,849(20.1)$ & 32,44 I (42.0) & $65,408(16.0)$ & I3,482 (I5.0) & $\mathrm{I}, 886(32.3)$ & II,596 (I3.8) \\
\hline
\end{tabular}

Notes: Prescription fills of oral tetracycline or topical corticosteroid were during the 2-year period, not necessarily at the same time as the cyclosporine prescription fill, and not necessarily for dry eye.

with $25.8 \%$ of nonprimary dry eye patients. In the chronic primary dry eye subset, $67.7 \%$ of patients filled a prescription for at least one of those three types of therapies (Table 6).

\section{Discussion}

The key role of inflammation in the pathogenesis of dry eye has been established in recent years based on analyses of inflammatory mediators and immunohistopathologic studies in animal models and dry eye patients, as well as through clinical trials of anti-inflammatory therapies. The present study was specifically designed to assess patterns of use of the anti-inflammatory therapy topical cyclosporine in dry eye patients. In this analysis of medical and pharmacy claims, $14.4 \%$ of dry eye patients filled a prescription for cyclosporine over the 2-year study period. The likelihood of dry eye patients receiving and filling a prescription for topical cyclosporine was dependent on whether they had ever been coded by a physician with dry eye as a primary diagnosis during any outpatient visit. In fact, patients with any primary diagnosis of dry eye were approximately 2.5 times more likely $(15.9 \%$ versus $6.5 \%, P<0.0001)$ than patients with only a nonprimary diagnosis of dry eye to fill a cyclosporine prescription. The impact of the diagnosis of primary versus

Table 5 Topical corticosteroid prescriptions most commonly filled by dry eye patients ${ }^{\mathrm{a}}$

\begin{tabular}{|c|c|c|}
\hline $\begin{array}{l}\text { Generic } \\
\text { drug name }\end{array}$ & $\begin{array}{l}\text { Patients }^{b} \\
\text { with topical } \\
\text { corticosteroid } \\
\text { prescription fill, } \mathbf{n}\end{array}$ & $\begin{array}{l}\text { Percentage of all } \\
\text { patients with any } \\
\text { topical corticosteroid } \\
\text { prescription fill }\end{array}$ \\
\hline $\begin{array}{l}\text { Any topical } \\
\text { corticosteroid }\end{array}$ & III,33| & 100 \\
\hline Loteprednol & 51,223 & 46.0 \\
\hline Dexamethasone & 45,420 & 40.8 \\
\hline Prednisolone & 22,979 & 20.6 \\
\hline Fluoromethalone & $|2,25|$ & 11.0 \\
\hline Difluprednate & 555 & 0.5 \\
\hline
\end{tabular}

Notes: ${ }^{\text {AAll }}$ patients in the total dry eye group. Use of topical corticosteroid was not necessarily for dry eye; bsome patients filled prescriptions for more than one topical corticosteroid. nonprimary dry eye was also seen on a per visit basis, as a prescription for cyclosporine was filled within 30 days after $8.4 \%$ of the primary dry eye visits versus $4.7 \%$ of the nonprimary dry eye visits $(P<0.0001)$.

Dry eye is a chronic, progressive disease ${ }^{9,10}$ that may require long-term therapy. Within the study period, a majority of dry eye patients did not fill a prescription for a common pharmaceutical intervention or receive a punctal plug to address their dry eye symptoms. Even in patients with primary dry eye based on physician diagnosis, only $40.7 \%$ of patients received a pharmaceutical or surgical intervention for their dry eye over the 2-year period. While the analysis does not take into account interventions done prior to or after the study period, these data suggest that the majority of dry eye patients are either undertreated or may rely predominantly on over-the-counter and nonprescription options not captured in a claims database. With the exception of patients with frequent visits to an ophthalmologist or optometrist with primary complaints of dry eye, defined in the present study as patients with at least three or more primary dry eye visits over the 2-year study period, the majority of dry eye patients do not receive and fill an intervention designed to treat the underlying inflammation of dry eye.

Beginning in patients with moderate dry eye disease, the International Task Force panel recommended the use of topical anti-inflammatory therapies even in cases in which inflammation is not clinically apparent. ${ }^{7}$ While claims data did not provide information on the severity of dry eye, they did provide the opportunity to evaluate whether anti-inflammatory therapies were filled by dry eye patients. Overall, topical corticosteroids were filled by $15 \%$ of nonprimary dry eye patients and $20 \%$ of primary dry eye patients during the study period. Loteprednol, an ester corticosteroid, was the topical corticosteroid most commonly filled by the dry eye patients in this claims database. Prolonged use of any topical corticosteroid, even an ester corticosteroid, may lead to common corticosteroid side effects, such as elevated intraocular pressure. ${ }^{11}$ Although the International Task 
Table 6 Treatment and non-treatment of dry eye patients ${ }^{\mathrm{a}}$

\begin{tabular}{|c|c|c|c|c|c|}
\hline \multirow[t]{2}{*}{ Patient group } & \multirow[t]{2}{*}{$\mathbf{n}$} & \multicolumn{2}{|c|}{$\begin{array}{l}\text { Any pharmaceutical or surgical } \\
\text { intervention - cyclosporine, } \\
\text { corticosteroid, tetracycline, } \\
\text { or plugs, n (\%) }\end{array}$} & \multicolumn{2}{|c|}{$\begin{array}{l}\text { Any pharmaceutical intervention - } \\
\text { cyclosporine, corticosteroid, } \\
\text { or tetracycline, } n(\%)\end{array}$} \\
\hline & & Yes & No & Yes & No \\
\hline All dry eye patients & 576,416 & $222,058(38.5)$ & $354,358(6 \mid .5)$ & 195,625 (33.9) & 380,791 (66.I) \\
\hline Primary dry eye patients & 486,390 & 198,097 (40.7) & $288,293(59.3)$ & $172,405(35.5)$ & $313,985(64.5)$ \\
\hline Primary chronic dry eye patients & 38,290 & $29,484(77.0)$ & $8,806(23.0)$ & $25,927(67.7)$ & $12,363(32.3)$ \\
\hline Nonprimary dry eye patients & 90,026 & $23,96 I(26.6)$ & $66,065(73.4)$ & $23,220(25.8)$ & $66,806(74.2)$ \\
\hline
\end{tabular}

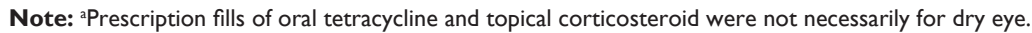

Force panel did not recommend initiating oral tetracyclines until level 3 disease, ${ }^{7}$ tetracylines are often utilized for their anti-inflammatory effects in addition to their antibacterial properties $^{12}$ and were utilized in approximately $11 \%$ of all dry eye patients.

Continued improvements in the objective clinical signs of dry eye occurred over the course of the 6-month Phase III trials of topical cyclosporine. ${ }^{13}$ Follow-up studies have subsequently demonstrated improvements in standard dry eye endpoints, including mean Schirmer values, at 12 and 24 months with continued use. ${ }^{914}$ Topical cyclosporine thus offers a long-term therapeutic option for dry eye patients that targets underlying inflammation and is not associated with glaucoma or cataracts. In the present analysis, $18.0 \%$ of patients filled only a 1-month supply of topical cyclosporine, despite the fact that the Phase III trials were based on 6 months of continued use. While the reasons for treatment discontinuation in this claims analysis are not available, other studies have demonstrated that burning and stinging associated with initial use of topical cyclosporine are common reasons for early discontinuation. ${ }^{15}$ Options previously reported to overcome this burning and stinging include patient education ${ }^{15}$ and adjunctive use of short courses of topical corticosteroids at initiation of topical cyclosporine, particularly in patients with more severe dry eye. ${ }^{16}$

The present study also sought to assess medication utilization within a subgroup of patients defined in this analysis as chronic primary dry eye patients, based on frequent visits over the study period specifically coded as primary dry eye visits. This patient population accounted for only $6.6 \%$ of all dry eye patients. While nearly half (48.2\%) of this patient population filled a prescription for topical cyclosporine during the study period, the patients in this group tended to have a greater number of office visits for dry eye (2.22 visits versus 1.54 visits) relative to the overall dry eye population prior to receiving and filling a prescription for cyclosporine. Although the design of the current claims analysis study, based on a 2-year window in time, does not allow full assessment, the higher percentage use of this medication in association with a greater number of prior office visits may indicate that physicians are delaying anti-inflammatory treatments such as topical cyclosporine until later in the treatment algorithm. In this patient population, this simply led to repeat office visits prior to patients receiving this particular therapeutic option specifically indicated for increasing tear production.

Both the International Task Force guidelines for the treatment of dry eye ${ }^{7}$ and the American Academy of Ophthalmology Preferred Practice guidelines for dry eye ${ }^{17}$ recommend treatment with topical cyclosporine and/or topical corticosteroids prior to punctal plugs, because blocking tear drainage with punctal plugs may result in retention of inflammatory mediators on the ocular surface and exacerbation of ocular surface damage and patient discomfort. ${ }^{7}$ In this study, approximately one third (31.2\%) of the patients who had a punctal plug procedure during the 2008-2009 period also filled a prescription for cyclosporine. Analysis of the order of treatment showed that among patients who had both punctal plug placement and a prescription for cyclosporine filled, the prescription fill typically occurred prior to punctal plug placement (59\% of patients), consistent with current guidelines.

This claims database study has several inherent limitations. As previously stated, claims analysis does not allow one to determine the severity of disease. The results reflect prescription fill patterns rather than prescribing patterns, as patients may have been given prescriptions and chosen not to fill them. Some patients may not have been included within the database for the entire 2-year period because of changes in the insurance provider. The definition of primary dry eye for purposes of this study required coding by a physician on only a single visit, and may have included patients with sporadic dry eye associated with environmental causes. In addition, time was a component of the definition of chronic dry eye used, such that chronic primary dry eye patients may have had more time in the study to receive a prescription. Adherence to cyclosporine treatment can only 
be estimated from prescription fills, and the patient may not use a fresh vial each morning and night as prescribed, or use all of the vials of cyclosporine received. The timing and order of prescription fills for topical cyclosporine and other medications was not analyzed, and no information is available with respect to whether these treatments were used sequentially or concomitantly. Finally, it was assumed for purposes of this analysis that the use of oral tetracylines and topical corticosteroids was for dry eye, although none of these products are indicated to treat dry eye.

In this retrospective claims study, $14.4 \%$ of dry eye patients filled at least one prescription for topical cyclosporine during the 2-year study period. This analysis demonstrates that dry eye patients seen on an outpatient visit in which dry eye is coded as the primary diagnosis for the visit are more likely to receive and fill a prescription for topical cyclosporine than those patients with dry eye complaints not coded as the primary reason for the outpatient visit. The demographics of those who fill a prescription for topical cyclosporine are similar to the demographics of patients with dry eye in general. Approximately one third of dry eye patients received an anti-inflammatory medication over the course of 2 years. The data included in this study reveal the habits of the patient and prescribing physician population, both of which are ever-changing. Studies such as this will help physicians better understand patient patterns in chronic disease processes such as dry eye disease.

\section{Disclosure}

This study was sponsored by Allergan, Inc. Medical writing assistance in the preparation of the manuscript was provided by Kate Ivins of Evidence Scientific Solutions and funded by Allergan, Inc. KGS is a consultant to Allergan, Inc.; JC, AO, $\mathrm{LV}$, and DAH are employees of Allergan, Inc.

\section{References}

1. [No authors listed]. The definition and classification of dry eye disease: report of the Definition and Classification Subcommittee of the International Dry Eye WorkShop (2007). Ocul Surf. 2007;5(2): 75-92.
2. Lemp MA. Report of the National Eye Institute/Industry workshop on Clinical Trials in Dry Eyes. CLAO J. 1995;21(4):221-232.

3. Schaumberg DA, Sullivan DA, Buring JE, Dana MR. Prevalence of dry eye syndrome among US women. Am J Ophthalmol. 2003;136(2): 318-326.

4. Schaumberg DA, Dana R, Buring JE, Sullivan DA. Prevalence of dry eye disease among US men: estimates from the Physicians' Health Studies. Arch Ophthalmol. 2009;127(6):763-768.

5. [No authors listed]. The epidemiology of dry eye disease: report of the Epidemiology Subcommittee of the International Dry Eye WorkShop (2007). Ocul Surf. 2007;5(2):93-107.

6. Miljanović B, Dana R, Sullivan DA, Schaumberg DA. Impact of dry eye syndrome on vision-related quality of life. Am J Ophthalmol. 2007;143(3):409-415.

7. Behrens A, Doyle JJ, Stern L, et al; the Dysfunctional Tear Syndrome Study Group. Dysfunctional tear syndrome: a Delphi approach to treatment recommendations. Cornea. 2006;25(8):900-907.

8. Lemp MA. Epidemiology and classification of dry eye. Adv Exp Med Biol. 1998;438:791-803.

9. Rao SN. Topical cyclosporine $0.05 \%$ for the prevention of dry eye disease progression. J Ocul Pharmacol Ther. 2010;26(2):157-164.

10. Gayton JL. Etiology, prevalence, and treatment of dry eye disease. Clin Ophthalmol. 2009;3:405-412.

11. Rajpal RK, Digby D, D'Aversa G, Mah F, Hollander DA, Conway T. Intraocular pressure elevations with loteprednol etabonate: a retrospective chart review. J Ocul Pharmacol Ther. 2011;27(3):305-308.

12. [No authors listed]. Management and therapy of dry eye disease: report of the Management and Therapy Subcommittee of the International Dry Eye WorkShop (2007). Ocul Surf. 2007;5(2):163-178.

13. Sall K, Stevenson OD, Mundorf TK, Reis BL. Two multicenter, randomized studies of the efficacy and safety of cyclosporine ophthalmic emulsion in moderate to severe dry eye disease. CsA Phase 3 Study Group. Ophthalmology. 2000;107(4):631-639.

14. Rao SN. Reversibility of dry eye deceleration after topical cyclosporine 0.05\% withdrawal. J Ocul Pharmacol Ther. 2011;27(6):603-609.

15. Mah F, Milner M, Yiu S, Donnenfeld E, Conway TM, Hollander DA. PERSIST: Physician's Evaluation of Restasis ${ }^{\circledR}$ Satisfaction in Second Trial of topical cyclosporine ophthalmic emulsion $0.05 \%$ for dry eye: a retrospective review. Clin Ophthalmol. 2012;6:1971-1986.

16. Byun YJ, Kim TI, Kwon SM, et al. Efficacy of combined $0.05 \%$ cyclosporine and $1 \%$ methylprednisolone treatment for chronic dry eye. Cornea. 2012;31(5):509-513.

17. American Academy of Ophthalmology Cornea/External Disease Panel. Preferred Practice Pattern ${ }^{\circledR}$ Guidelines. Dry Eye Syndrome - Limited Revision. San Francisco, CA: American Academy of Ophthalmology; 2011. Available from: http://one.aao.org/CE/PracticeGuidelines/ PPP_Content.aspx?cid=127dbdce-4271-471a-b6d9-464b9d15b748. Accessed September 14, 2013.
Therapeutics and Clinical Risk Management

\section{Publish your work in this journal}

Therapeutics and Clinical Risk Management is an international, peerreviewed journal of clinical therapeutics and risk management, focusing on concise rapid reporting of clinical studies in all therapeutic areas, outcomes, safety, and programs for the effective, safe, and sustained use of medicines. This journal is indexed on PubMed Central, CAS,

\section{Dovepress}

EMBase, Scopus and the Elsevier Bibliographic databases. The manuscript management system is completely online and includes a very quick and fair peer-review system, which is all easy to use. Visit http://www.dovepress.com/testimonials.php to read real quotes from published authors. 